\title{
Methamphetamine Hydrochloride
}

National Cancer Institute

\section{Source}

National Cancer Institute. Methamphetamine Hydrochloride. NCI Thesaurus. Code C47609.

The hydrochloride salt form of methamphetamine, an amphetamine and sympathomimetic amine with CNS stimulating properties. Methamphetamine hydrochloride acts by facilitating the release of catecholamines, particularly noradrenaline and dopamine, from nerve terminals in the brain and inhibits their uptake. This leads to an increase in synaptic concentration of these neurotransmitters and results in an increase of motor activity, causes euphoria, mental alertness and excitement and suppresses appetite. Methamphetamine hydrochloride causes dependence and may cause an increase in heart rate and blood pressure. 